\title{
THE ROLE OF CAREER DEVELOPMENT TOOLS IN ENHANCING PROACTIVE BEHAVIOR
}

\author{
Azman Ismail ${ }^{1}$, Wan Aishah Wan Mohd Nowalid ${ }^{2}$ \\ 1,2 Universiti Kebangsaan Malaysia, Bangi, Selangor, Malaysia \\ azisma12@ukm.edu.my
}

\begin{abstract}
This study aims at measuring the relationship between career development tools and proactive behaviour using self-report questionnaires collected from workers at an oil and gas service company in Peninsular Malaysia. The results of linear regression analysis displayed two major findings: first, job autonomy was positively and significantly related to proactive behaviour. Second, transformational leadership was positively and significantly related to proactive behaviour. In overall, this result demonstrates that the career development tools act as an important predictor of employees' proactive behavior in the organizational sample. Further, this study provides discussion, implications and conclusion.

Keywords: Career Development Tools, Proactive Behavior, Malaysia, SPSS
\end{abstract}

JEL $\quad:$ D23; O15

DOI $\quad: 10.24002 /$ kinerja.v22i1.1566

Received : 03/08/2017 Reviewed : 15/01/2018 Final Version : 27/03/2018 


\section{INTRODUCTION}

Career program is often seen as an important function of human resource development and management (Azman, et al., 2015; Wong, et al., 2017). It refers to the role of human resource managers in designing and administering the entire stage, process, attitude, behavior and situation which related to employees' work well-being in organizations (Antoniu, 2010; Gomez-Mejia, Balkin \& Cardy, 2016). In carrying out the role, human resource managers will often collaborate and liaise with other department heads to set up a master career plan in order to achieve the following aims: retain top talent, enhance engagement and productivity, reinforce succession planning, generate knowledge transfer and retention, fill internal skill and role gaps, as well as build positive employer branding (Insala, 2017). Implementation of the career plan at organizational and departmental levels may strongly motivate employees to maintaining and supporting their organizational strategy and goals in an era of global economy (Crawford, Monson \& Searle, 2016; Clarke, 2017).

A review of the recent literature pertaining to human resource development shows that the design of career programs will not achieve its aim if management does not have capabilities to appropriately implement career development tools in organizations (Hadjisolomou, 2015; Bocciardi, et al., 2017). In an organizational development perspective, career development tools are generally viewed as an organization takes initiatives to assist its employees in achieving their career goals (Wong, et al., 2017; Guerrero, Jeanblanc \& Veilleux, 2016). According to many scholars like Sia and Appu (2015), Rono and Kiptum (2017), Anitha and Aruna (2016), specifically state that career development consists of two influential tools: job autonomy and transformational leadership.

In an organizational career, job autonomy (JOTY) is often viewed as employees' freedom to determine work methods, work schedules, and decision making in executing daily job operations (Gagne \& Deci, 2005; Anitha \& Aruna, 2016; Montgomery, 2017). While, transformational leadership (TRLP) is usually seen as the ability of leaders to use charisma (inspire and motivate followers), intellectual stimulation (challenge followers to higher levels of performance), individualized consideration (personal attention to every followers) and idealized influence (role model for followers) in executing their organizational goals (Bass \& Avolio, 1994; Suifan \& Al-Janini, 2017).

Extant studies in competitive organization reveal that the ability of management to properly implement job autonomy and transformational leadership in evolving employee careers may have a significant impact on employee outcomes, especially proactive behavior (De Jong, et al., 2015; Marinova, et al., 2015; Zee, 2016; Wu \& Parker, 2017). In a human attitude and behaviour perspective, proactive behaviour (PROB) is broadly defined as individuals who have capabilities to use proactive personalities, maintain social networking and 
manage career behaviour in achieving their career objectives in organizations (Crant, 2000; King, 2004; Huang, 2016; Yang \& Chau, 2016).

Within a career management model, many scholars think that JOTY, TRLP and PROB have different meanings, but highly interconnected concepts. Even though the nature of this relationship is interesting, the role of career development tools as an important predicting variable has been ignored in the context of oil and gas industry (Edwin, 2015). Many scholars debate that this condition may be caused by several factors: first, a number of earlier studies have much described the conceptual definitions and different types of career prospect in oil and gas companies (Idris \& Manganaro, 2017; OilJobFinder, 2017; Harhara, Singh, \& Hussain, 2015; ShaleNET, 2013). Second, many past studies have much discussed the characteristics of career development program, such as conceptual definitions, purposes, types and benefits of career development tools in oil and gas companies. On the contrary, the effect of specific career development tools (i.e., job autonomy and transformational leadership) on employees' proactive behaviour has not been adequately discussed in the oil and gas companies (Bloomfield, 2015; Insala, 2017; Yu, 2010).

Third, many previous researches have been conducted by oil and gas company officers and consultants using an applied research methodology to develop career programs and link their effect on specific job structure issues, especially upstream, midstream and downstream activities, as well as pay levels and structures for workers (Bloomfield, 2015; Insala, 2017; ShaleNET, 2013). In an applied research methodology, a simple descriptive and correlation as well as secondary data are often utilized to predict outcomes and solve practical problems (Harhara, Singh \& Hussain, 2015; ShaleNET, 2013; Yu, 2010). As a result, the above studies have only offered general findings and this may not sufficient to be used as guiding principles by practitioners in understanding the complexity of career development tool concept and establishing innovation plans to support ultimate career development objectives in oil and gas industry.

Therefore, these reasons inspire the researchers to fill in the gap of literature by assessing the effect of career development tools on proactive behaviour. Specifically, the present study intends to answer two important objectives: first, to assess the relationship between job autonomy and proactive behaviour. Second, to assess the relationship between transformational leadership and proactive behaviour. 


\section{RELATIONSHIP BETWEEN CAREER DEVELOPMENT TOOLS AND PROACTIVE BEHAVIOR}

The importance of career development tools as a predicting variable has gained strong support from the notion of career management theory. For example, Herzberg's (1966) motivator-hygiene theory states the importance of internal job factors such as recognition, achievement, possibility of growth, advancement, responsibility and work itself in enhancing positive individuals' actions. Application of this theory in career management shows that the notion of internal job motivation factors is often driven by job autonomy (De Jong, et al., 2015; Marinova, et al., 2015). On the contrary, Fiedler's $(1964,1967)$ leader-match theory posits that leaders who are able to select leadership styles that suite with the particular conditions may motivate followers to support their goals. Application of this theory in career management shows that that the notion of leader-match and is often viewed as transformational leadership (Rank, 2006; Northouse, 2013). Further, transformational leadership theory explains that idealized influence, inspirational motivation, intellectual stimulation and individualized consideration are important leadership practices in affecting followers to achieve their goals in organizations (Bass \& Riggio, 2006; Fogelqvist \& Lestander, 2017). The notion of these theories has gained strong support from the career management research literature.

Previous empirical researches showed that effect of career development tools on proactive behavior had produced mixed results. For example, studies by several researchers, such as Parker, Williams \& Turner (2006) used a sample of 282 wire makers in U.K. and Paramitha \& Indarti (2014) used sample of 132 employees working in mass media industry in Indonesia. Results from these studies showed that leader's support did not act as an important determinant of employees' proactive behaviour in the organizations. This finding is due to diverse employees have different values and assessments about the importance of support types provided by management in the organizations (Frese \& Fay, 2001).

Further, latest researches have provided strong evidences that career development tools are important determinants of proactive behaviour in dynamic organizations. For example, results from surveys of 179 employees in a Dutch research and consultancy organization (De Jong, et al., 2015), 28,402 metaanalytic tests (Marinova, et al., 2015), 146 trainees from the financial sector (Zee, 2016), 138 employees from United State and 212 employees from a large gas and oil company in China (Wu \& Parker, 2017) displayed two important findings: first, the ability of leaders to appropriately implement autonomy in doing daily job operations had enhanced employees' proactive behavior (De Jong, et al., 2015; Marinova, et al., 2015). Second, the ability of leaders to appropriately implement transformational styles in performing daily work had enhanced employees' proactive behavior (Zee, 2016; Wu \& Parker, 2017). Thus, it was hypothesized that: 
$\mathrm{H} 1$ : There is a positive relationship between JOTY and PROB

H2: There is a positive relationship between TRLP and PROB

\section{METHODOLOGY}

A cross-sectional research design was utilized because it allowed the researchers to combine the workplace career literature, and the actual survey as a main procedure to collect data for this study. The use of this procedure may collect accurate data, less biased data and high quality data (Creswell, 1998; Sekaran, 2000). This study was conducted at an oil and gas company in West Malaysia. At the initial stage of this study, a survey questionnaire was developed based on the workplace career management literature. Then, a back translation technique was employed to translate the survey questionnaires into Malay and English versions in order to enhance the validity and reliability of research results (Creswell, 1998; Wright, 1996).

The survey questionnaire has 3 parts: first, JOTY was assessed using 17 items adapted from career program literature (Breaugh, 1985; Parrish, 2001; Saragih, 2011; Goussinsky, 2015). The dimensions used to measure this construct were work method, work scheduling and decision making. Second, TRLP was had 15 items that were adapted from career management related transformational leadership (Callow, et. al, 2009; Rank, 2006; Zee, 2016). The dimensions used to measure this construct were charismatic, inspirational motivation, idealized influence and intellectual stimulation. Third, PROB had 9 items that were adapted from career management related proactive behaviour (Owens, 2009; Forret \& Dougherty, 2001; Barnett \& Bradley, 2007; Huang, 2016). The dimensions used to measure this construct were proactive personality, networking and career management behaviour. The above items were assessed using a 7 -item scale ranging from "strongly disagree/dissatisfied" (1) to "strongly agree/satisfied" (7). Respondent characteristics were used as controlling variables because this study concerned on employee attitudes.

A purposive sampling technique was employed to distribute 200 survey questionnaires to employees work in the organization. This sampling technique was employed in this study because the list of registered employees was not given to the researchers for confidential reasons and this condition did not allow to choose participants randomly from the population. Of the total number, 132 (66 percent) usable questionnaires were returned to the researchers. The survey questions were answered by participants based on their consent and on a voluntary basis. Further, the Statistical Package for Social Sciences (SPSS) was used to assess the validity and reliability of instrument and test the research hypotheses. 


\section{FINDINGS}

The majority respondents were male (56.8 percent), Malaysian (97.7 percent), aged between 25 to 34 years old (64.4 percent), degree holders (47.7 percent), employees who in management and professional level (59.1 percent), employees who served from 5 to 14 years (52.3 percent), permanent employees (76.5 percent), employees who had monthly salaries starting from RM4000 and above (50.0 percent), and married (68.9 percent).

Table 1 shows the results of validity and reliability analyses for the instrument. The questionnaires had 41 items, which related to three variables: JOTY (17 items), TRLP (15 items), and PROB (9 items). The factor analysis with direct oblimin rotation and Kaiser-Mayer-Olkin Test (KMO) were conducted for each variable. The results showed that: first, all research variables exceeded the acceptable standard of Kaiser-MeyerOlkin's value of 0.6 and all research variables were significant in Bartlett's test of sphericity, indicating the sample used in this study was adequate (Hair, et al., 1998). Second, all research variables had eigenvalues larger than 1 , and the items for each research variable exceeded factor loadings of 0.40 , indicating that the variables met the criteria of validity analysis (Hair, et al., 1998). Finally, all research variables had the values of Cronbach alpha greater than 0.70 , indicating that the variables met the requirements of reliability analysis (Nunally \& Bernstein, 1994). These statistical results confirm that the instrument has met the acceptable standards of validity and reliability analyses.

Table 2 shows the results of descriptive statistics and Pearson correlation analysis. The mean values for the variables are between 4.37 and 5.77, signifying the levels of JOTY, TRLP, and PROB ranging from high (4) to highest level (7). The correlation coefficients for the relationship between the independent variable (i.e., JOTY and TRLP) and the dependent variable (i.e., PROB) were less than 0.90 , indicating that the data were not affected by serious collinearity problem (Hair, et al., 1998). These statistical results further confirm that the variables have satisfactorily met the criteria of validity and reliability analyses.

Table 3 shows that the inclusion of job autonomy in the analysis had explained 29 percent in the variance of proactive behavior, showing that it provided a moderate support for the overall model (Chin, 2001). Specifically, the outcomes of testing hypothesis displayed two major findings: first, JOTY was positively and significantly correlated with proactive behaviour $(\beta=0.224 ; p=0.029)$, therefore $\mathrm{H} 1$ was supported. Second, TRLP was positively and significantly correlated with PROB ( $\beta=0.249 ; p=0.013)$, therefore $\mathrm{H} 2$ was supported. This result demonstrates that JOTY and TRLP is an important predictor of proactive behaviour in the studied organization. 
Table 1. Validity and Reliability of the Instrument

\begin{tabular}{lccccccc}
\hline Measure & Items & $\begin{array}{c}\text { Factor } \\
\text { Loadings }\end{array}$ & KMO & $\begin{array}{c}\text { Bartlett's Test } \\
\text { of Sphericity }\end{array}$ & Eigenvalue & $\begin{array}{c}\text { Variance } \\
\text { Explained }\end{array}$ & $\begin{array}{c}\text { Cronbach } \\
\text { Alpha }\end{array}$ \\
\hline JOTY & 17 & $\begin{array}{c}0.510 \text { to } \\
0.828\end{array}$ & 0.912 & 1622.21 & 8.821 & 51.890 & 0.940 \\
TRLP & 15 & $\begin{array}{c}0.504 \text { to } \\
0.740\end{array}$ & 0.888 & 1056.46 & 7.271 & 48.470 & 0.921 \\
PROB & 9 & $\begin{array}{c}0.543 \text { to } \\
0.866\end{array}$ & 0.900 & 1216.63 & 6.371 & 70.785 & 0.948 \\
\hline
\end{tabular}

Table 2. Descriptive Statistics and Pearson Correlation Analysis

\begin{tabular}{lccccc}
\hline \multicolumn{1}{r}{ Variables } & Mean & $\begin{array}{c}\text { Standard } \\
\text { Deviation }\end{array}$ & \multicolumn{3}{c}{ Pearson Correlation $(r)$} \\
& & & 1 & 2 & 3 \\
\hline 1. JOTY & 5.64 & .646 & 1 & & \\
2. TRLP & 5.77 & .531 & $.614^{* *}$ & 1 & \\
3. PROB & 4.37 & 1.043 & $.390^{* *}$ & $.379^{* *}$ & 1
\end{tabular}

Note: Correlation Value is significant at ${ }^{* *} p<0.01$ Reliability estimation are shown diagonally (value 1 ) 
Table 3. The Outcomes of Linear Regression Analysis Showing the Relationship between Career Management and Proactive Behavior

\begin{tabular}{|c|c|c|}
\hline \multirow[t]{2}{*}{ Variable } & \multicolumn{2}{|c|}{$\begin{array}{l}\text { Dependent Variable } \\
\text { (PROB) }\end{array}$} \\
\hline & Step 1 & Step 2 \\
\hline \multicolumn{3}{|l|}{$\underline{\text { Controlling Variable }}$} \\
\hline Gender & -.178 & -.132 \\
\hline Race & .039 & .059 \\
\hline Age & -.051 & .015 \\
\hline Education & -.113 & -.114 \\
\hline Position & .167 & .145 \\
\hline Length of Service & .114 & .056 \\
\hline Type of Service & $.210^{*}$ & .138 \\
\hline Monthly Income & -.048 & -.114 \\
\hline Marital Status & $-.241^{* *}$ & $-.199^{*}$ \\
\hline \multicolumn{3}{|l|}{ Independent Variable } \\
\hline JOTY & & $.224^{\star}$ \\
\hline TRLP & & $.249^{\star \star}$ \\
\hline R Square & 0.121 & 0.288 \\
\hline Adjust R Square & 0.057 & 0.223 \\
\hline R Square change & 0.121 & 0.167 \\
\hline $\mathrm{F}$ & 1.872 & $4.415^{\star \star \star}$ \\
\hline $\mathrm{F} \Delta \mathrm{R}$ Square & $1.872^{\star \star \star}$ & $14.054^{\star \star \star}$ \\
\hline
\end{tabular}

Note: ${ }^{*} \mathrm{p}<0.05,{ }^{* *}<0.01,{ }^{* * *} \mathrm{p}<0.001$ Beta $=$ Standardized Beta

As an extension of the hypothesis testing, the variance inflation factor was further conducted to test the relationship between the variables of interest. The results of this test showed that the relationship between JOTY and PROB was 1.717; and relationship between TRLP and PROB was 1.651. These values were less than 0.10 , indicating that they were not affected by a serious collinearity problem (Hair, et al., 1998). 


\section{DISCUSSION AND IMPLICATIONS}

The result of this study shows that career development tools act as an important predictor of proactive behavior. In the context of this study, leaders (management employees) have designed and administered the various kinds of career programs to meet different workers' needs and expectations based on broad policies and procedures as established by their stakeholders. Majority respondents view that the levels of JOTY, TRLP and PROB are high. This condition describes that the readiness of management to appropriately implement job autonomy and transformational leadership to achieve their targets may lead to greater workers' proactive behaviour in the organizations.

This study provides three major implications: theoretical contribution, robustness of research methodology, and contribution to practitioners. In terms of theoretical contribution, the finding of this study is consistent with the notion of Herzberg's (1966) motivator-hygiene theory, Fiedler's $(1964,1967)$ leader-match theory, and Bass and Riggio's (2006) transformational leadership theory reveals that the ability of management to appropriately implement career development tools may strongly invoke employees' proactive behaviour in the organization. This result also has supported and broadened studies by De Jong, et al., (2015), Marinova, et al., (2015), Zee (2016), Wu \& Parker (2017). With respect to the robustness of research methodology, the survey questionnaires used in this study had met the requirements of validity and reliability analyses. This situation may lead to produced accurate and reliable research results.

Regarding with practical contribution, the outcomes of this study may be used as useful recommendations by leaders to improve employee careers in organizations. In order to perform this objective, top management needs to focus on the following issues: firstly, performance management should be encouraged to assist leaders in using formal and/or informal performance appraisal systems to develop employee performance in achieving organizational objectives. Secondly, communication openness should be promoted to reduce interaction gap, increase understanding about career prospects and cooperation between employees in achieving career goals. Thirdly, interactive training methods (e.g., mentoring, coaching, counselling and case studies) should be updated to ease employees in understanding theoretical knowledge and enhancing practical skills in planning, managing and monitoring the progression of their career paths in organizations. Finally, the type, level and/or amount of reward should be upgraded according to job structure and merit. This change will help employees to receive adequate rewards and may strongly attract, retain and motivate employees to support their organization strategy and goals. If top management concerns on the above suggestions this may strongly motivate employees to perform the organizational career objectives. 


\section{CONCLUSION}

This study confirms that JOTY and TRLP are important predictors of PROB in the organization. Therefore, current research and practice within the human capital development model needs to view JOTY and TRLP as a crucial dimension of the workplace career management domain. This study further suggests that the capability of leaders to appropriately implement job autonomy and transformational leadership in achieving their targets will strongly induce subsequent positive employee outcomes (e.g., satisfaction, commitment and performance). Thus, this positive behaviour may lead to greater organizational competitiveness and productivity in an era of knowledge based economy.

This study has several limitations: firstly, the data was only taken one time during the length of this study and it did not describe detail differences in the sample. Secondly, this study only assesses the relationship between latent variables and the conclusion drawn from this study does not show the relationship between specific elements for the independent variable and the dependent variable. Thirdly, this study only focused on particular career development tools and neglected other important elements (e.g., job structure and work culture). Finally, the sample for this study was collected using a purposive sampling plan in a single private company. These limitations may decrease the ability of generalizing the results of this study to other organizational situations.

This study provides several suggestions to reinforce future research. Firstly, certain important organizational and personal characteristics (e.g., job type, working condition, gender, age, education and marital status) should be included in the analysis and this may clarify different effect of career development tools in organizations. Secondly, longitudinal research design may be used to collect less bias and accurate data because it describes detail sub-sample perceptions toward causal relationships between variables of interest. Thirdly, the findings of this study would produce better findings if it is done in more than one organizations. Fourthly, other theoretical constructs of career development tools such as counselling, mentoring, coaching and support should be considered because they have been widely acknowledged as an important link between career management and work outcomes. Finally, other outcome constructs such as satisfaction, commitment, performance, ethics and prosocial behaviour need to be assessed because they are found important in the workplace career program research literature. The importance of these matters needs to be further discovered in future research.

\section{Acknowledgement}

We would like to thank to research assistants who have invested a lot of time and energies to collect and key in survey questionnaire data into the SPSS/PC+. They are Eulis Ratnaningsih Adedodos Akhmad, Harnyzurina Mohd Ibrahim, Lailatool Nuqiah Muhammad and Norhamamah Jamaluddin. 


\section{REFERENCES}

Anitha, J. and Aruna, M., 2016. Enablers of employee engagement of Gen $Y$ at the workplace with reference to Automobile Sector. Amity Journal of Training and Development, 1(1), pp.93-108.

Antoniu, E., 2010. Career planning process and its role in human resource development. Annals of the University of Petroşani, Economics, 10(2), pp.13-22.

Azman, I., Wan Aishah, W.M.N., Nurrul Hayati, A., Hasan Al-Banna, M. and Raja Rizal Iskandar, R.H., 2015. Hubungan antara peranan pengurus dalam program kerjaya dengan pembangunan kelakuan proaktif pekerja. Global Journal Al-Thaqafah, 5(1), pp.81-103.

Barnett, B.R. and Bradley, L., 2007. The impact of organisational support for career development on career satisfaction. Career Development International, 12(7), pp.617-636.

Bass, B. and Riggio, R., 2006. Transformational leadership. 2nd ed. Mahwah, N.J: Lawrence Erlbaum Associates.

Bass, B.M. and Avolio, B.J., 1994. Improving organizational effectiveness through transformational leadership. Thousand Oaks, CA. Sage Publications.

Bloomfield, G., 2015. 8 reasons why you should work in the oil and gas sector. Available at: https://engineering-jobs.theiet.org/article/8-reasons-why-youshould-work-in-the-oil-and-gas-sector/ [Accessed 10 July 2017].

Bocciardi, F., Caputo, A., Fregonese, C., Langher, V. and Sartori, R., 2017. Career adaptability as a strategic competence for career development: An exploratory study of its key predictors. European Journal of Training and Development, 41(1), pp.67-82.

Breaugh, J.A., 1985. The Measurement of Work Autonomy. Human Relations, 6, pp.551-570.

Callow, N., Smith, M.J., Hardy, L., Arthur, C.A. and Hardy, J., 2009. Measurement of transformational leadership and its relationship with team cohesion and performance level. Journal of Applied Sport Psychology, 21, pp.395-412.

Chin. W.W., 2001. PLS-Graph User's Guide: Version 3.0. Houstan, TX: Soft Modelling.

Clarke, M., 2017. Building employability through graduate development programmes: A case study in an Australian public sector organisation. Personnel Review, 46(4), pp.792-808.

Crant, J.M., 2000. Proactive behavior in organizations. Journal of Management, 26(3), pp.435-462.

Crawford, R., Monson, K. and Searle, J., 2016. Mentoring tertiary students from a secondary school incubator programme focusing on health careers: Findings from a New Zealand study. Journal of Applied Research in Higher Education, 8(4), pp.424-438. 
Creswell, J.W., 1998. Qualitative Inquiry and Research Design: Choosing Among Five Traditions. London: Sage Publications.

De Jong, J.P.J., Parker, S.K., Wennekers, S. \& Wu, Chia-Huei. 2015. Entrepreneurial behavior in organizations: Does job design matter? Entrepreneurship Theory and Practice 39(4): 981-995.

Edwin, A. 2015., Training and development in the Oil and Gas Industry. Journal of Business Administration and Management Sciences Research, 4(9), pp.197-207.

Fiedler, F.E., 1964. A contingency model of leadership effectiveness. In L. Berkowitz (Ed.), Advances in experimental social psychology, 1, 149-190. Academic Press, New York, USA.

Fiedler, F.E., 1967. A Theory of Leadership Effectiveness. New York, USA: McGraw-Hill

Fogelqvist, P. and Lestander, H., 2017. Transformational leadership and motivation in sport: The moderating role of personality and self-other agreement ratings. Master thesis. Umea University.

Forret, M.L. and Dougherty, T.W., 2001. Correlates of networking behavior for managerial and professional Employees. Group \& Organization Management. (25), pp.283-311.

Frese, M. and Fay, D., 2001. Personal initiative: An active performance concept for work in the 21st century. Research in Organizational Behavior, 23, pp. 133187.

Gagne, M. and Deci, E.L., 2005. Self-determination theory and work motivation. Journal of Organizational Behavior, (26), pp.331-362.

Gomez-Mejia, L.R., Balkin, D. and Cardy, R., 2016. Managing Human Resources. 8th ed. Hoboken, NJ: Pearson.

Goussinsky, R., 2015. Customer aggression, felt anger and emotional deviance: The moderating role of job autonomy. International Journal of Quality and Service Sciences, 7(1), pp.50-71.

Guerrero, S., Jeanblanc, H. and Veilleux, M., 2016. Development idiosyncratic deals and career success. Career Development International, 21(1), pp.1930 .

Hadjisolomou, A., 2015. Managing attendance at work: The role of line managers in the UK grocery retail sector. Employee Relations, 37(4), pp.442-458.

Hair, J.F., Anderson, R.E., Tatham, R.L. and Black, W.C., 1998. Multivariate Data Analysis. 5th ed. New Jersey: Prentice Hall International, Inc.

Harhara, A.S., Singh, S.K. and Hussain, M., 2015. Correlates of employee turnover intentions in oil and gas industry in the UAE. International Journal of Organizational Analysis, 23(3), pp.493-504.

Herzberg, F., 1966. Work and the Nature of Man. Cleveland: World Publishing Company. 
Huang, Y.M., 2016. Networking behaviour: From goal orientation to promotability. Personnel Review, 45(5), pp.907-927.

Idris, A.M. and Manganaro, M., 2017. Relationships between psychological capital, job satisfaction, and organizational commitment in the Saudi oil and Petrochemical industries. Journal of Human Behavior in the Social Environment, 27(4), pp.251-269.

Insala., 2017. Career development: the benefits. Available at http://www.insala.com/career-development-benefits.asp [Accessed 11 July 2017).

King, Z., 2004. Career self-management: its nature, causes and consequences. Journal of Vocational Behavior, 65, pp.112-133.

Marinova, S.V., Peng, C., Lorinkova, N., Dyne, L.V. and Chiaburu, D., 2015. Change-oriented behavior: A meta-analysis of individual and job design predictors. Journal of Vocational Behavior 8, pp.104-120.

Montgomery, A.R., 2017. Impact of job characteristics and resources on person-job fit. Master thesis. Faculty of California State University, San Bernardino.

Northouse, P.G., 2013. Leadership: Theory and Practice. Sixth Edition. Thousand Oaks: Sage Publications, Inc

Nunally, J.C. and Bernstein, I.H. 1994. Psychometric Theory. New York: McGrawHill.

OilJobFinder., 2017. Your gateway to oil and gas industry jobs. Available at http://www.oiljobfinder.com/ [Accessed 12 July 2017].

Owens, J.J., 2009. Examining the relationship between proactive personality and career success. Master thesis. The University of Tennessee at Chattanooga.

Paramitha, A. and Indarti, N., 2014. Impact of the environment support on creativity: Assessing the mediating role of intrinsic motivation. Procedia Social and Behavioral Sciences, 115, pp.102-114.

Parker, S.K., Williams, H.M. and Turner, N., 2006. Modeling the antecedents of proactive behavior at work. Journal of Applied Psychology, 91(3), pp. 636652.

Parrish, D.A., 2001. The impact of leadership behavior on organizational commitment and job autonomy of information services Librarians. Doctoral dissertation. The Florida State University.

Rank, J., 2006. Leadership predictors of proactive organizational behavior: Facilitating personal initiative, voice behavior, and exceptional service performance. Graduate School Theses and Dissertations. University of South Florida.

Rono, E.J. and Kiptum, G.K., 2017. Factors affecting employee retention at the University of Eldoret, Kenya. Journal of Business and Management, 19(3), pp.109-115. 
Saragih, S., 2011. The effects of job autonomy on work outcomes: Self efficacy as an intervening variable. International Research Journal of Business Studies, 4(3), pp.203-215.

Sekaran, U., 2000. Research Methods for Business: A Skill Building Approach. New York: John Wiley \& Sons, Inc.

ShaleNET. 2013. A Guide to careers in the oil and natural gas industry. Available at http://careerguide.shalenet.org/Content/guides/CareerGuide2013.pdf [Accessed 10 July 2017].

Sia, S.K. and Appu, A.V., 2015. Work autonomy and workplace creativity: Moderating role of task complexity. Global Business Review, 16(5), pp.772784.

Suifan, T.S. and Al-Janini, M., 2017. The relationship between transformational leadership and employees' creativity in the Jordanian Banking Sector. International Review of Management and Marketing, 7(2), pp.284-292.

Wong, S.C., Mohd Rasdi, Roziah., Abu Samah, Bahaman and Abdul Wahat, Nor Wahiza., 2017. Promoting protean career through employability culture and mentoring: Career strategies as moderator. European Journal of Training and Development, 41(3), pp.277-302.

Wright, L.L., 1996. Qualitative International Management Research. In: Punnett, B.J., and Shenkar, $\mathrm{O}$ (Eds.), Handbook for International Management Research (pp. 63-81). Oxford, UK: Blackwell Publishers Inc.

Wu, C.H. and Parker, S.K., 2017. The role of leader support in facilitating proactive work behaviour: A perspective from attachment theory. Journal of Management, 43(4), pp.1025-1049.

Yang, F. and Chau, R., 2016. Proactive personality and career success. Journal of Managerial Psychology, 31(2), pp.467-482.

$\mathrm{Yu}, \mathrm{J} ., 2010$. Careers in the oil and gas industry, from start to finish. Available at http://talentegg.ca/incubator/2010/11/22/careers-in-the-oil-and-gas-industryfrom-start-to-finish/ [Accessed 11 July 2017].

Zee, W.V.D., 2016. Managing high potential employees: the impact of transformational leadership on behavioural outcomes and the moderation effect of role stress. Master thesis, School of Social and Behavioural Science, Tilburg University. 